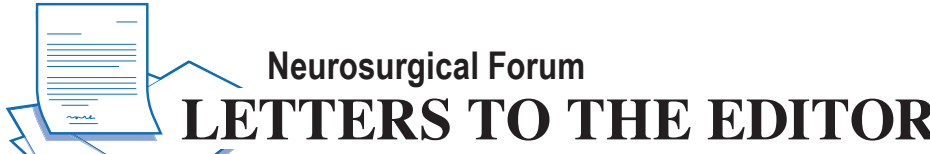 $\longrightarrow<$
}

\section{Risk factors for shunt dependency after aneurysmal subarachnoid hemorrhage}

TO THE EDITOR: We read with great interest the article by Wilson et al. ${ }^{21}$ (Wilson CD, Safavi-Abbasi S, Sun $\mathrm{H}$, et al: Meta-analysis and systematic review of risk factors for shunt dependency after aneurysmal subarachnoid hemorrhage. J Neurosurg [epub ahead of print April 1, 2016. DOI: 10.3171/2015.11.JNS152094]), in which a comprehensive meta-analysis had been conducted and several risk factors for shunt dependency in patients with aneurysmal subarachnoid hemorrhage (aSAH) were identified. Their findings were helpful for risk stratification in the assessment of patients with aSAH. However, some more issues should be addressed.

Firstly, the criteria for shunt dependency were not specified in this meta-analysis. According to the American Heart Association/American Stroke Association guidelines, chronic symptomatic hydrocephalus requires shunt placement. ${ }^{4}$ However, 2 of the studies ${ }^{8,16}$ included in the meta-analysis focused on risk factors associated with hydrocephalus instead of shunt dependency. Therefore, we believe that these studies should not be included. Secondly, 2 included studies focused on the aSAH patients with external ventricular drain (EVD) placement. ${ }^{2,3}$ Since some studies reported EVD placement as a risk factor for shunt dependency, $18,19,23,24$ we recommend performing a subgroup analysis (general patients group and EVD placement group). Thirdly, though the study from Lai and Mor-

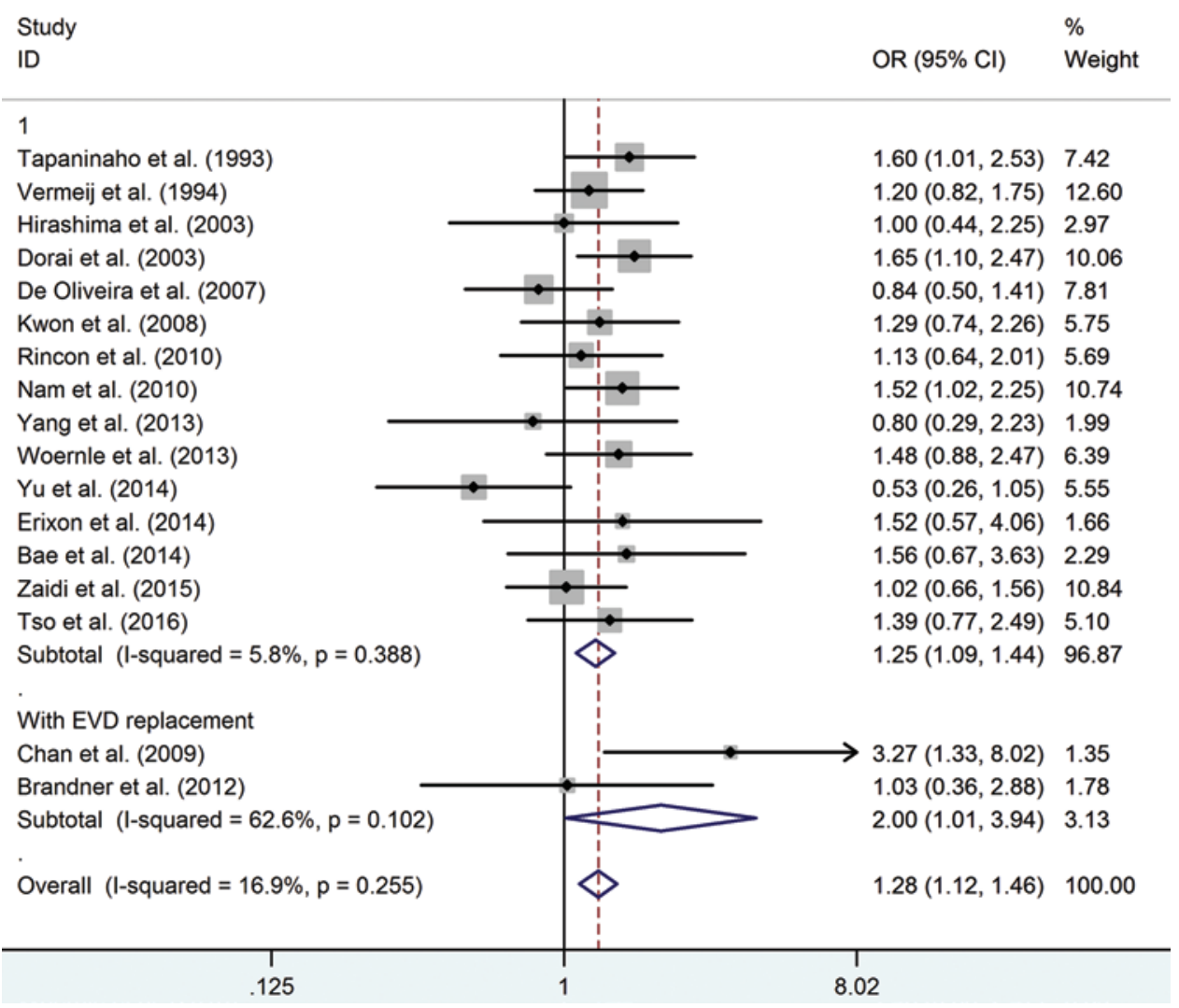

FIG. 1. Forest plot for female sex as a risk factor for shunt dependency after aSAH. Figure is available in color online only. 
gan had the largest population, the selection bias was not a negligible issue. Since the Australian National Hospital Morbidity Database was unable to track the data on aSAH patients beyond discharge from acute-care hospitals, data on patients with delayed or chronic hydrocephalus might not be captured. ${ }^{13}$ This bias may explain the reason that study reported the lowest shunt rate $(6.5 \%)$ among all the included studies. Therefore, we recommend performing a sensitivity analysis by excluding that study to verify whether the results remain robust.

Fourthly, female sex did not reach statistical significance as a risk factor in this meta-analysis. However, according to the study inclusion criteria, some more studies should be considered eligible. . $^{1,10,11,18,25}$ When adding data from these studies, we detected a significantly increased risk of shunt dependency in female aSAH patients (Fig. 1; OR $1.28,95 \%$ CI 1.12-1.46).

Fifthly, it was suggested that neurosurgical clipping might improve cerebrospinal fluid circulation and reduce the risk of shunt dependency by early evacuation of cisternal clot and blood products. ${ }^{9}$ However, Wilson et al. did not explore whether treatment modalities could influence the risk of shunt dependency.

Zhiyi Xie, MD
Xin Hu, MD
Hao Li, MD
Sen Lin, MD
Chao You, MD

West China Hospital, Sichuan University, Chengdu, Sichuan, P. R. China

\section{References}

1. Bae IS, Yi HJ, Choi KS, Chun HJ: Comparison of incidence and risk factors for shunt-dependent hydrocephalus in aneurysmal subarachnoid hemorrhage patients. J Cerebrovasc Endovasc Neurosurg 16:78-84, 2014

2. Brandner S, Xu Y, Schmidt C, Emtmann I, Buchfelder M, Kleindienst A: Shunt-dependent hydrocephalus following subarachnoid hemorrhage correlates with increased S100B levels in cerebrospinal fluid and serum. Acta Neurochir Suppl 114:217-220, 2012

3. Chan M, Alaraj A, Calderon M, Herrera SR, Gao W, Ruland $\mathrm{S}$, et al: Prediction of ventriculoperitoneal shunt dependency in patients with aneurysmal subarachnoid hemorrhage. J Neurosurg 110:44-49, 2009

4. Connolly ES, Jr., Rabinstein AA, Carhuapoma JR, Derdeyn CP, Dion J, Higashida RT, et al: Guidelines for the management of aneurysmal subarachnoid hemorrhage: a guideline for healthcare professionals from the American Heart Association/American Stroke Association. Stroke 43:1711-1737, 2012

5. de Oliveira JG, Beck J, Setzer M, Gerlach R, Vatter H, Seifert V, et al: Risk of shunt-dependent hydrocephalus after occlusion of ruptured intracranial aneurysms by surgical clipping or endovascular coiling: a single-institution series and meta-analysis. Neurosurgery 61:924-934, 2007

6. Dorai Z, Hynan LS, Kopitnik TA, Samson D: Factors related to hydrocephalus after aneurysmal subarachnoid hemorrhage. Neurosurgery 52:763-771, 2003

7. Erixon HO, Sorteberg A, Sorteberg W, Eide PK: Predictors of shunt dependency after aneurysmal subarachnoid hemorrhage: results of a single-center clinical trial. Acta Neurochir (Wien) 156:2059-2069, 2014

8. Graffradford NR, Torner J, Adams HP, Kassell NF: Factors associated with hydrocephalus after subarachnoid hemorrhage. A report of the Cooperative Aneurysm Study. Arch Neurol 46:744-752, 1989

9. Gruber A, Reinprecht A, Bavinzski G, Czech T, Richling B: Chronic shunt-dependent hydrocephalus after early surgical and early endovascular treatment of ruptured intracranial aneurysms. Neurosurgery 44:503-509, 1999

10. Hirashima Y, Hamada H, Hayashi N, Kuwayama N, Origasa $\mathrm{H}$, Endo S: Independent predictors of late hydrocephalus in patients with aneurysmal subarachnoid hemorrhage - analysis by multivariate logistic regression model. Cerebrovasc Dis 16:205-210, 2003

11. Komotar RJ, Hahn DK, Kim GH, Khandji J, Mocco J, Mayer SA, et al: The impact of microsurgical fenestration of the lamina terminalis on shunt-dependent hydrocephalus and vasospasm after aneurysmal subarachnoid hemorrhage. Neurosurgery 62:123-134, 2008

12. Kwon JH, Sung SK, Song YJ, Choi HJ, Huh JT, Kim HD: Predisposing factors related to shunt-dependent chronic hydrocephalus after aneurysmal subarachnoid hemorrhage. J Korean Neurosurg Soc 43:177-181, 2008

13. Lai L, Morgan MK: Predictors of in-hospital shunt-dependent hydrocephalus following rupture of cerebral aneurysms. J Clin Neurosci 20:1134-1138, 2013

14. Nam KH, Hamm IS, Kang DH, Park J, Kim YS: Risk of shunt dependent hydrocephalus after treatment of ruptured intracranial aneurysms: surgical clipping versus endovascular coiling according to Fisher grading system. J Korean Neurosurg Soc 48:313-318, 2010

15. Rincon F, Gordon E, Starke RM, Buitrago MM, Fernandez A, Schmidt JM, et al: Predictors of long-term shunt-dependent hydrocephalus after aneurysmal subarachnoid hemorrhage. Clinical article. J Neurosurg 113:774-780, 2010

16. Sheehan JP, Polin RS, Sheehan JM, Baskaya MK, Kassell NF: Factors associated with hydrocephalus after aneurysmal subarachnoid hemorrhage. Neurosurgery 45:1120-1128, 1999

17. Tapaninaho A, Hernesniemi J, Vapalahti M, Niskanen M, Kari A, Luukkonen M, et al: Shunt-dependent hydrocephalus after subarachnoid haemorrhage and aneurysm surgery: timing of surgery is not a risk factor. Acta Neurochir (Wien) 123:118-124, 1993

18. Tso MK, Ibrahim GM, Macdonald RL: Predictors of shuntdependent hydrocephalus following aneurysmal subarachnoid hemorrhage. World Neurosurg 86:226-232, 2016

19. Varelas P, Helms A, Sinson G, Spanaki M, Hacein-Bey L: Clipping or coiling of ruptured cerebral aneurysms and shunt-dependent hydrocephalus. Neurocrit Care 4:223-228, 2006

20. Vermeij FH, Hasan D, Vermeulen M, Tanghe HL, van Gijn J: Predictive factors for deterioration from hydrocephalus after subarachnoid hemorrhage. Neurology 44:1851-1855, 1994

21. Wilson CD, Safavi-Abbasi S, Sun H, Kalani MYS, Zhao YD, Levitt MR, et al: Meta-analysis and systematic review of risk factors for shunt dependency after aneurysmal subarachnoid hemorrhage. J Neurosurg [epub ahead of print April 1, 2016. DOI: 10.3171/2015.11.JNS152094]

22. Woernle CM, Winkler KM, Burkhardt JK, Haile SR, Bellut D, Neidert MC, et al: Hydrocephalus in 389 patients with aneurysm-associated subarachnoid hemorrhage. J Clin Neurosci 20:824-826, 2013

23. Yang TC, Chang CH, Liu YT, Chen YL, Tu PH, Chen HC: Predictors of shunt-dependent chronic hydrocephalus after aneurysmal subarachnoid haemorrhage. Eur Neurol 69:296-303, 2013

24. Yu H, Zhan R, Wen L, Shen J, Fan Z: The relationship between risk factors and prognostic factors in patients with shunt-dependent hydrocephalus after aneurysmal subarachnoid hemorrhage. J Craniofac Surg 25:902-906, 2014 
25. Zaidi HA, Montoure A, Elhadi A, Nakaji P, McDougall CG, Albuquerque FC, et al: Long-term functional outcomes and predictors of shunt-dependent hydrocephalus after treatment of ruptured intracranial aneurysms in the BRAT trial: revisiting the clip vs coil debate. Neurosurgery 76:608-614, 2015

\section{Disclosures}

The authors report no conflict of interest.

\section{Response}

We thank Dr. You and colleagues for their interest in our article. Indeed, there are many variables to be considered and we appreciate their suggestions.

Christopher D. Wilson, MD

Sam Safavi-Abbasi, MD, PhD

Robert F. Spetzler, MD

On behalf of the authors

Barrow Neurological Institute, St. Joseph's Hospital and Medical Center,

Phoenix, AZ

\section{INCLUDE WHEN CITING}

Published online September 2, 2016; DOI: 10.3171/2016.5.JNS161244.

cAANS, 2017

\section{Evoked potentials and Chiari malformation Type 1}

TO THE EDITOR: We read with interest the study by Moncho et al. ${ }^{9}$ (Moncho D, Poca MA, Minoves T, et al: Are evoked potentials clinically useful in the study of patients with Chiari malformation Type 1? J Neurosurg [epub ahead of print April 15, 2016. DOI: 10.3171/2015.11. JNS151764]). In their retrospective analysis of prospectively collected data, the authors suggest that evoked potential aberrations in preoperative workup of patients with Chiari malformation Type 1 (CM-1) do not contribute to establishment of treatment algorithms, yet somatosensory evoked potential (SSEP) and brainstem auditory evoked potential (BAEP) changes may help to establish evidence of subclinical dysfunctions.

In the accompanying editorial, ${ }^{1}$ Dr. Adelson describes the complexity of decision making in these cases and the inability of electrophysiological testing to indicate either dysfunction or disease progression, which also emphasizes the unestablished indications for preoperative nerve monitoring evaluation.

The role of intraoperative evoked potential monitoring in CM-1, traditionally using SSEP and BAER modalities (auditory brainstem response), remains, in our opinion, unclear. In our recent study ${ }^{2}$ we addressed this issue in addition to questioning the potential benefit of adding transcranial motor evoked potential (TcMEP) monitoring to the equation in an attempt to improve sensitivity and specificity to detect postoperative deficits. We presented data that demonstrate that the use of multimodality intraoperative neurophysiological monitoring (INM), including TcMEP, could be beneficial in detecting and avoiding iatrogenic injury stemming from inappropriate patient positioning and could possibly contribute to the decision-making process of deciding when adequate decompression has been achieved on an individual-patient basis.

As was the case for image-guided neuronavigation that began as a useful tool in neurosurgical procedures and today is widespread and often considered standard of care, INM is rapidly becoming a "must" in various surgeries, including treatment of brainstem and spinal cord tumors, $, 6,70$ tethered cord syndrome, ${ }^{4}$ scoliosis and other spinal deformities,,${ }^{3,8}$ syringomyelia, ${ }^{13}$ and degenerative cervical spine disorders, ${ }^{5}$ as well as supratentorial surgery. ${ }^{11,12}$

In the modern era of neurosurgery, and when taking into account factors of "defensive medicine," prioritization in the use of INM as a surgical adjunct must be addressed. In this light, we see Moncho and colleagues' study as an opportunity to call attention to this dilemma and urge further large-scale studies regarding the role of electrophysiological testing in CM-1 both preoperatively and intraoperatively.

Ori Barzilai, MD Jonathan Roth, MD

Akiva Korn, MMedSc, D-ABNM

"Dana" Children's Hospital, Tel Aviv Medical Center, Tel Aviv, Israel

Shlomi Constantini, MD, MSc

Tel Aviv, "Sourasky" Medical Center, Tel Aviv, Israel

\section{References}

1. Adelson PD: Editorial. Evoked potentials and Chiari malformation Type 1. J Neurosurg [epub ahead of print April 15, 2016. DOI: 10.1371/2015.11.JNS152624]

2. Barzilai O, Roth J, Korn A, Constantini S: The value of multimodality intraoperative neurophysiological monitoring in treating pediatric Chiari malformation type I. Acta Neurochir (Wien) 158:335-340, 2016

3. Burke D, Hicks R, Stephen J, Woodforth I, Crawford M: Assessment of corticospinal and somatosensory conduction simultaneously during scoliosis surgery. Electroencephalogr Clin Neurophysiol 85:388-396, 1992

4. Husain AM, Shah D: Prognostic value of neurophysiologic intraoperative monitoring in tethered cord syndrome surgery. J Clin Neurophysiol 26:244-247, 2009

5. Kelleher MO, Tan G, Sarjeant R, Fehlings MG: Predictive value of intraoperative neurophysiological monitoring during cervical spine surgery: a prospective analysis of 1055 consecutive patients. J Neurosurg Spine 8:215-221, 2008

6. Korn A, Halevi D, Lidar Z, Biron T, Ekstein P, Constantini S: Intraoperative neurophysiological monitoring during resection of intradural extramedullary spinal cord tumors: experience with 100 cases. Acta Neurochir (Wien) 157:819-830, 2015

7. Kothbauer KF, Deletis V, Epstein FJ: Motor-evoked potential monitoring for intramedullary spinal cord tumor surgery: correlation of clinical and neurophysiological data in a series of 100 consecutive procedures. Neurosurg Focus 4(5):e1, 1998

8. Langeloo DD, Journée HL, de Kleuver M, Grotenhuis JA: Criteria for transcranial electrical motor evoked potential monitoring during spinal deformity surgery A review and discussion of the literature. Neurophysiol Clin 37:431-439, 2007 
9. Moncho D, Poca MA, Minoves T, Ferré A, Cañas V, Sahuquillo J: Are evoked potentials clinically useful in the study of patients with Chiari malformation Type 1 ? J Neurosurg [epub ahead of print April 15, 2016; DOI: 10.3171/2015.11.JNS151764]

10. Morota N, Deletis V, Constantini S, Kofler M, Cohen H, Epstein FJ: The role of motor evoked potentials during surgery for intramedullary spinal cord tumors. Neurosurgery 41:1327-1336, 1997

11. Neuloh G, Pechstein U, Cedzich C, Schramm J: Motor evoked potential monitoring with supratentorial surgery. Neurosurgery 61:337-348, 2007

12. Nossek E, Korn A, Shahar T, Kanner AA, Yaffe H, Marcovici $\mathrm{D}$, et al: Intraoperative mapping and monitoring of the corticospinal tracts with neurophysiological assessment and 3 -dimensional ultrasonography-based navigation. Clinical article. J Neurosurg 114:738-746, 2011

13. Pencovich N, Korn A, Constantini S: Intraoperative neurophysiologic monitoring during syringomyelia surgery: lessons from a series of 13 patients. Acta Neurochir (Wien) 155:785-791, 2013

\section{Disclosures}

The authors report no conflict of interest.

\section{Response}

We would like to thank Dr. Barzilai and colleagues for their letter regarding our recent paper on the BAEP and SSEP alterations found in patients with CM-1. We are familiar with Dr. Barzilai's studies in the field of INM in treating pediatric CM- $1,{ }^{4}$ and therefore his interest and comments on our work are greatly appreciated. At the same time, his letter gives us the opportunity to broaden the discussion and address the still-controversial topic of the usefulness and clinical relevance of intraoperative evoked potential monitoring in patients with CM-1.

The application of INM has expanded rapidly over the past 2 decades, as seen in the large number of studies published in different disciplines, including neurosurgery, neurophysiology, orthopedic and vascular surgery, otolaryngology, and neurology. The main objective of INM is to protect the vulnerable neural structures by allowing early detection of reversible neurophysiological dysfunction during surgery, thus preventing permanent neurological damage. INM is a very interesting field, not only from a clinical point of view, but also because it is an attractive instrument for research..$^{10}$ At present, however, there is still much to learn and do in order to demonstrate the real benefit of these techniques in some pathologies. Given the current low volume of evidence, we do not agree with Dr. Barzilai and colleagues' opinion that INM may be used as an instrument of "defensive" medicine. As far as we know, no studies have shown the sensitivity, specificity, and predictive values (either positive or negative) of INM in CM-1 patients. This is a requirement for any diagnostic tool to be routinely used in the operating room. In addition, INM increases anesthesia, surgical time, and monetary costs and, when applied to CM-1 surgery, can lead to erroneous, or at least questionable, decisions.

Some authors have proposed INM during surgery in patients with CM-1, mainly in the following 3 scenarios: 1) during placement of the patient before surgery, 2) to determine when adequate decompression has been achieved and therefore to design surgery on an individualized basis, and 3) to detect intraoperative evoked potential worsening.

For surgical positioning in patients with CM-1, the rationale for intraoperative evoked potential monitoring is that it can diminish the risk of neurological injury at a time when it can be reversed. Anderson et al. reported the case of a 14-year-old patient with CM-1 and a holocord syrinx who underwent suboccipital decompressive craniectomy and in whom surgical positioning had to be modified after a dramatic deterioration of baseline SSEPs. ${ }^{2}$ After the patient's neck was repositioned, the left median nerve potential improved but did not return to baseline. Postoperatively, the patient had decreased proprioception of the left arm that persisted for 2 weeks. ${ }^{2}$ In that case report, the first figure shows that the patient had severe CM, with the obex below the foramen magnum, significant tonsillar descent, and possible basilar impression with anterior compression. Using the new classification, this patient would have been included in the category of CM Type 1.5 (CM-1.5), or even been diagnosed as having a complex craniocervical junction malformation. Other studies have reported that the patients with impaired evoked potentials during surgical positioning were those with complex craniovertebral junction abnormalities. ${ }^{9}$

At our center, surgery is always performed with the patient in the prone position, with cranial flexion and discrete cervical distraction, and the head fixed in the Mayfield headholder. In all patients, a tolerance test is always performed before surgery: the patient is asked to maintain cervical hyperflexion-similar to that used during surgery-for at least 2.5 hours while they carry out a routine activity, such as reading. The few patients reporting neurological symptoms during this test are placed with their neck in a neutral position. After treating more than 300 patients with $\mathrm{CM}-1$, we have not detected any neurological complications related to head positioning. However, we agree with Dr. Barzilai and colleagues that evoked potential monitoring during head positioning may be useful in some CM patients, especially those with more severe malformations who are at risk for neck flexion.

The most controversial aspect of this topic is, in our opinion, the use of INM to limit the degree of posterior fossa decompression (PFD) and guide the decision of whether or not to open the dura mater. Some authors have argued that an extradural approach-that is, suboccipital craniectomy with a C-1 laminectomy and resection of the fibrous band at the level of foramen magnum, with eventual serial incisions of the outer layer of the dura without opening it-is enough to relieve the pressure gradient at the craniocervical junction and improve clinical symptoms. ${ }^{5}$ Intraoperative ultrasonography and/or BAEP monitoring have been used by several authors to decide whether to open the dura in $\mathrm{CM}$ patients, especially children. Zamel et al. reported that PFD involving bone removal alone significantly improved conduction time in BAEPs in most pediatric patients with $\mathrm{CM}-1^{12}$ and that the use of duraplasty allowed for a greater improvement in conduction time in only $20 \%$ of patients when compared to surgery involving bone decompression alone. ${ }^{12}$ Anderson et al. reported improved BAEP conduction times in most patients who had undergone PFD with duraplasty, but the authors stated that 
the majority of improvements were also observed after bony decompression. ${ }^{3}$ These results suggest that opening the dura mater is not necessary in the treatment of CM, especially in patients without syringomyelia. However, in the Zamel series, postoperative brain MRI studies were only available for 55 of the 80 patients treated and showed normalization of the position of the cerebellar tonsils in only $54.5 \%$ of patients in whom a pure extradural approach was taken; this rate increased to $84 \%$ in patients who underwent duraplasty. ${ }^{12}$ Similar negative findings were observed in the position of the cerebellar tonsils on the postoperative MRI studies of most of the 30 pediatric patients with CM-1 treated by Caldarelli and colleagues using a purely extradural procedure. ${ }^{5}$ Taking into account these results, we cannot consider that optimal treatment was applied based on evoked potential findings.

It is well known that opening the dura mater and carrying out a dural graft increase the risk of CSF leakage, pseudomeningocele, and aseptic meningitis. However, restoring "normal" CSF circulation through the foramen magnum is essential in the surgical treatment of CM. It is well established that PFD and duraplasty achieve the best results in the treatment of $\mathrm{CM}$, regardless of whether it is associated with syringomyelia or not, $, 7,11$ in both adults and children. This has also been the case in most CM-1 patients admitted to our department for a second-look surgery after an extradural procedure (see example in Fig. 1).
It is also important to note the potent osteogenic effect of the dura mater in the process of calvarial regeneration, ${ }^{6}$ which can explain the partial posterior fossa reossification observed in some pediatric patients with CM-1 treated without duraplasty (Fig. 2). In terms of security, we want to emphasize that when surgery involves wide suboccipital craniectomy, resection of the posterior arch at C-1 and opening the dura with preservation of the arachnoid membrane (a surgical technique we named "posterior fossa reconstruction" in 1994) ${ }^{8}$ produces excellent morphological results, with cranial ascent of the hindbrain, good clinical outcomes, and minimal complications. This technique has been used in most patients who undergo this type of surgery at our institution for the last 20 years.

With regard to the use of evoked potentials for monitoring neurological worsening during surgery, Zamel and coworkers' study reported that none of the 80 children with CM-1 in whom BAEPs were monitored showed any significant worsening during surgery that would have prompted the surgical team to modify their surgical strategy. ${ }^{12}$ Similarly, of the 22 patients of the Barzilai et al. study, none had evoked potential alterations during surgery, although 3 patients displayed significant SSEP attenuation concomitant with patient positioning. ${ }^{4}$ These findings confirm that the incidence of neurological complications once the patient is positioned is very low ${ }^{9}$ and therefore raise doubt about the cost-effectiveness of this procedure.
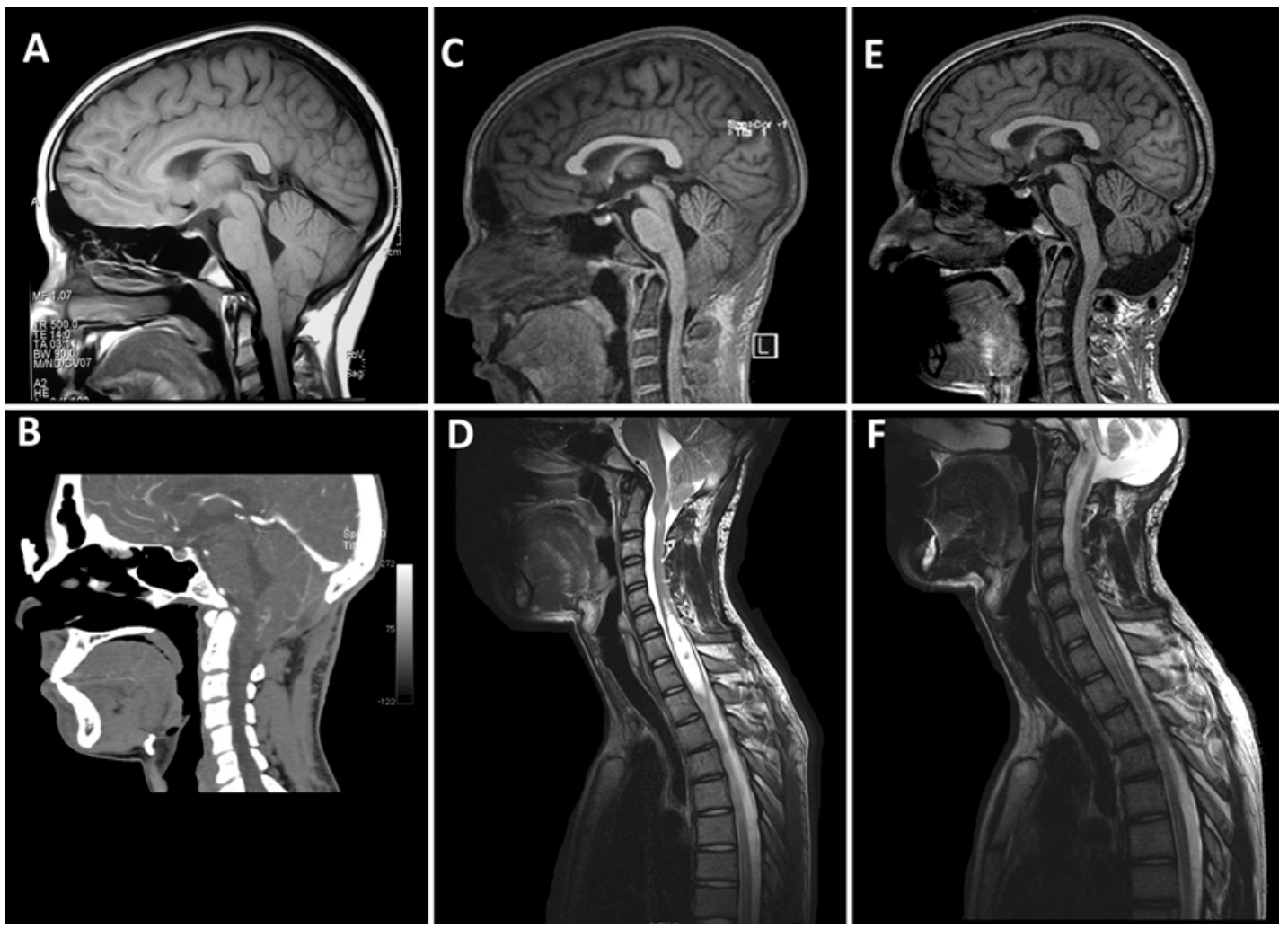

FIG. 1. Presurgical MR image (A) and sagittal CT scan (B) in an 11-year-old boy with CM-1.5 and a moderate basilar impression, in whom a PFD was performed at another institution without opening the dura mater (B). The postoperative control images 4 years after surgery ( $C$ and $\mathbf{D}$ ) did not show any change in the cerebellar tonsil position or in the size and extension of the syringomyelia. The patient underwent a second surgery at the age of 16 years, involving an increased occipital bone resection, opening of the dura mater, and a wide duraplasty. The postoperative MR images ( $E$ and $F$ ) showed cerebellar remodeling with a large pseudocisterna magna, a significant tonsillar repositioning, and a small residual syrinx. 

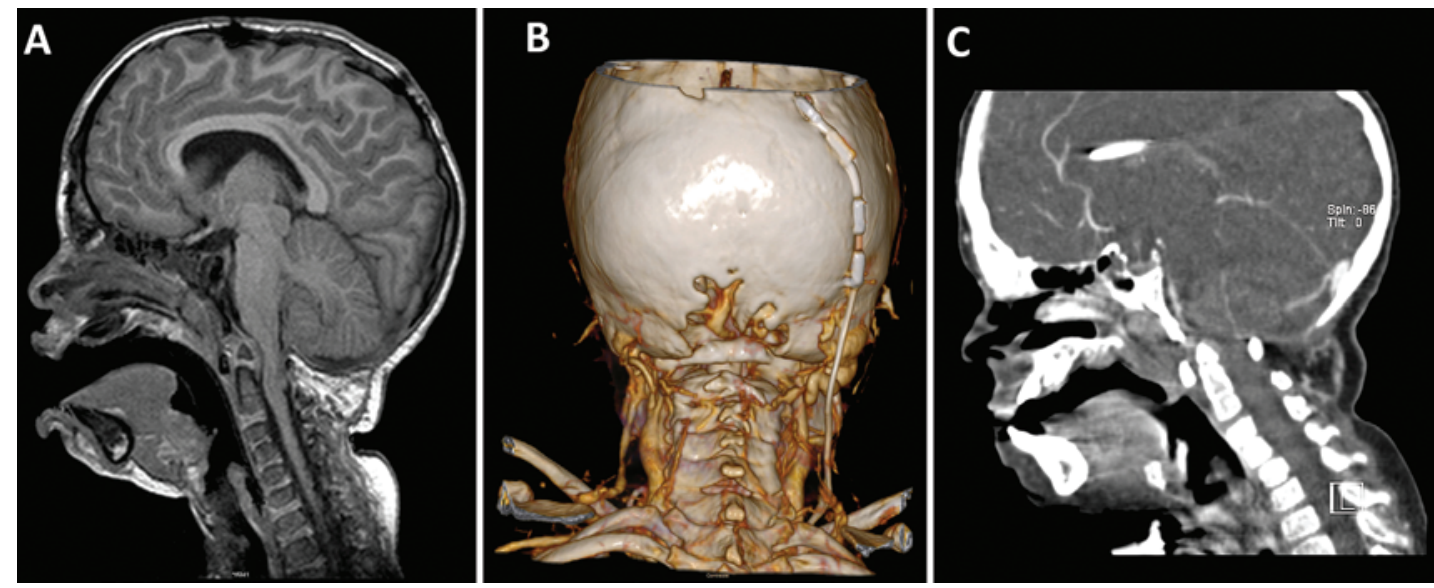

FIG. 2. A 6-year-old girl with a treated syndromic craniosynostosis who, when she was 6 months old, underwent PFD without opening the dura mater. Follow-up MR image (A) obtained when she was referred to our institution at the age of 4 . At the age of 6 , a follow-up CT scan showed a partial reossification of the occipital bone (B and C). Figure is available in color online only.

We completely agree with Dr. Barzilai and colleagues' opinion that there is a need to establish an optimal, costeffective monitoring protocol for posterior fossa surgery in patients with CM-1. ${ }^{4}$ However, the evidence to date shows that the only potential benefit of evoked potential monitoring in CM-1 is during patient positioning and only in a small number of patients who could most likely be identified before surgery, making the routine use of INM difficult to justify.

\section{Maria A. Poca, MD, PhD Dulce Moncho, MD Juan Sahuquillo, MD, PhD} Vall d'Hebron University Hospital, Vall d'Hebron Research Institute, Universitat Autònoma de Barcelona, Barcelona, Spain

\section{References}

1. Alamar M, Teixidor P, Colet S, Muñoz J, Cladellas JM, Hostalot C, et al: [Comparison [corrected] of Chiari I malformation treatment using suboccipital craniectomy and posterior arch of $\mathrm{C} 1$ resection with or without dural graft.] Neurocirugia (Astur) 19:233-241, 2008 (Span)

2. Anderson RC, Emerson RG, Dowling KC, Feldstein NA: Attenuation of somatosensory evoked potentials during positioning in a patient undergoing suboccipital craniectomy for Chiari I malformation with syringomyelia. J Child Neurol 16:936-939, 2001

3. Anderson RC, Emerson RG, Dowling KC, Feldstein NA: Improvement in brainstem auditory evoked potentials after suboccipital decompression in patients with Chiari I malformations. J Neurosurg 98:459-464, 2003

4. Barzilai O, Roth J, Korn A, Constantini S: The value of multimodality intraoperative neurophysiological monitoring in treating pediatric Chiari malformation type I. Acta Neurochir (Wien) 158:335-340, 2016

5. Caldarelli M, Novegno F, Vassimi L, Romani R, Tamburrini G, Di Rocco C: The role of limited posterior fossa craniectomy in the surgical treatment of Chiari malformation Type I: experience with a pediatric series. J Neurosurg 106:187195,2007

6. Gosain AK, Santoro TD, Song LS, Capel CC, Sudhakar PV, Matloub HS: Osteogenesis in calvarial defects: contribution of the dura, the pericranium, and the surrounding bone in adult versus infant animals. Plast Reconstr Surg 112:515527,2003

7. Munshi I, Frim D, Stine-Reyes R, Weir BK, Hekmatpanah J, Brown F: Effects of posterior fossa decompression with and without duraplasty on Chiari malformation-associated hydromyelia. Neurosurgery 46:1384-1389, 2000

8. Sahuquillo J, Rubio E, Poca MA, Rovira A, Rodriguez-Baeza A, Cervera C: Posterior fossa reconstruction: a surgical technique for the treatment of Chiari I malformation and Chiari I/syringomyelia complex-preliminary results and magnetic resonance imaging quantitative assessment of hindbrain migration. Neurosurgery 35:874-884, 1994

9. Sala F, Squintani G, Tramontano V, Coppola A, Gerosa M: Intraoperative neurophysiological monitoring during surgery for Chiari malformations. Neurol Sci 32 (Suppl 3):S317S319, 2011

10 Simon MV (ed): Intraoperative Clinical Neurophysiology. A Comprehensive Guide to Monitoring and Mapping. New York: Demos Medical, 2010

11. Sindou M, Chavez-Machuca J, Hashish H: Cranio-cervical decompression for Chiari type I-malformation, adding extreme lateral foramen magnum opening and expansile duroplasty with arachnoid preservation. Technique and long-term functional results in 44 consecutive adult cases-comparison with literature data. Acta Neurochir (Wien ) 144:1005-1019, 2002

12. Zamel K, Galloway G, Kosnik EJ, Raslan M, Adeli A: Intraoperative neurophysiologic monitoring in 80 patients with Chiari I malformation: role of duraplasty. J Clin Neurophysiol 26:70-75, 2009

INCLUDE WHEN CITING

Published online September 9, 2016; DOI: 10.3171/2016.4.JNS161061.

cAANS, 2017

\section{Whole-brain CT perfusion and subarachnoid hemorrhage}

TO THE EDITOR: We read with keen interest the article by Malinova et al. ${ }^{3}$ (Malinova V, Dolatowski K, Schramm P, et al: Early whole-brain CT perfusion for de- 
tection of patients at risk for delayed cerebral ischemia after subarachnoid hemorrhage. J Neurosurg 125:128-136, July 2016). The authors have described the utility of wholebrain CT perfusion (CTP) in predicting the occurrence of delayed ischemic neurological deficits and delayed cerebral infarction in patients with acute subarachnoid hemorrhage (aSAH). We commend the authors for their study, which sheds light on the enigma of delayed ischemic neurological deficits and delayed cerebral infarction following aSAH. In days to come, CTP may become part of routine study in patients with aSAH.

Global cerebral edema (GCE) occurs after aSAH and is associated with functional and cognitive dysfunction. It usually occurs during the early phase (0-3 days) after aSAH. GCE is identified on CT scan by the following characteristics: 1) effacement of hemispheric sulci and basal cisterns, and 2) bilateral and extensive disruption of the cerebral gray-white matter junction at the level of the centrum semiovale., ${ }^{1,2}$ Patients with GCE have global perfusion deficits when compared to patients without GCE. ${ }^{1}$ This may affect early CT perfusion studies, and it probably was not considered by the authors. The number of such patients and the CTP findings in such patients should be addressed.

Acute hydrocephalus after aSAH is known to be associated with reduced cerebral blood flow in the deep gray matter and periventricular white matter. ${ }^{4}$ This could also have affected the results, and interpretation of this study and the number of patients with hydrocephalus have not been mentioned.

The authors' study has very few patients with Fisher Grade 2 SAH and no patient with Fisher Grade $1 \mathrm{SAH}$, and it may be very difficult to generalize the result of this study to patients in these two groups. Thus, a study with a larger patient population and one composed of these two groups needs to be done, considering the radiation and the use of contrast agents for CTP studies.

We once again commend the authors for this study and concur with them that a larger study group is required to compare various subgroups and to analyze the effects of CTP on outcome of patients with aSAH.

\section{Chinmaya Dash, MCh} Raghav Singla, MBBS All India Institute of Medical Sciences, New Delhi, India

\section{References}

1. Baradaran H, Fodera V, Mir D, Kesavobhotla K, Ivanidze J, Ozbek U, et al: Evaluating CT perfusion deficits in global cerebral edema after aneurysmal subarachnoid hemorrhage. Am J Neuroradiol 36:1431-1435, 2015

2. Claassen J, Carhuapoma JR, Kreiter KT, Du EY, Connolly ES, Mayer SA: Global cerebral edema after subarachnoid hemorrhage frequency, predictors, and impact on outcome. Stroke 33:1225-1232, 2002

3. Malinova V, Dolatowski K, Schramm P, Moerer O, Rohde V, Mielke D: Early whole-brain CT perfusion for detection of patients at risk for delayed cerebral ischemia after subarachnoid hemorrhage. J Neurosurg 125:128-136, 2016

4. Van Asch CJJ, van der Schaaf IC, Rinkel GJE: Acute hydrocephalus and cerebral perfusion after aneurysmal subarachnoid hemorrhage. AJNR Am J Neuroradiol 31:67-70, 2010

\section{Disclosures}

The authors report no conflict of interest.

\section{Response}

No response was received from the authors of the original article.

\section{INCLUDE WHEN CITING}

Published online November 25, 2016; DOI: 10.3171/2016.7.JNS161860.

(CAANS, 2017

\section{Recurrent or residual craniopharyngioma: management options}

TO THE EDITOR: I congratulate Dhandapani et al. ${ }^{1}$ for their excellent article (Dhandapani S, Singh H, Negm HM, et al: Endonasal endoscopic reoperation for residual or recurrent craniopharyngiomas. J Neurosurg [epub ahead of print May 6, 2016. DOI: 10.3171/2016.1.JNS152238]).

I want to comment on certain aspects of their study. The authors concluded that the endonasal endoscopic transsphenoidal approach for residual or recurrent craniopharyngioma results in resection and visual outcomes similar to those following first-time operations. ${ }^{1}$ As the extent of resection is influenced by prior radiation, they suggested that endonasal reoperations are preferred over radiation. However, the overall rates of gross-total resection (GTR) and GTR + near-total resection (NTR) in their study were $80 \%(28 / 35)$ and $86 \%(30 / 35)$ among primary tumors compared to $55 \%(12 / 22)$ and $68 \%(15 / 22)$ among reoperations. These overall outcomes may be more relevant than the rates calculated based on the 46 cases intended for GTR, especially since radiation is the standard option applicable for all residual or recurrent cases. ${ }^{2}$ As the endonasal reoperations involved patients both with and without prior radiation, the impacts of reoperation and radiation had some overlap. Hence, this differential impact would probably become clearer if the authors had presented the resection rates and visual outcomes among reoperations without prior radiation and reoperations following radiation separately in comparison to primary surgery.

\section{Anirudh Srinivasan, MCh (Neurosurgery) \\ Sakra World Hospital, Bangalore, Karnataka, India}

\section{References}

1. Dhandapani S, Singh H, Negm HM, Cohen S, Souweidane MM, Greenfield JP, et al: Endonasal endoscopic reoperation for residual or recurrent craniopharyngiomas. J Neurosurg [epub ahead of print May 6, 2016. DOI: 10.3171/2016.1.JNS152238]

2. PDQ Pediatric Treatment Editorial Board: Childhood craniopharyngioma treatment $(\mathrm{PDQ} \AA)$ : Health professional version. PDQ Cancer Information Summaries. (http:// www.ncbi.nlm.nih.gov/books/NBK65891/) [Accessed October 27, 2016] 


\section{Disclosures}

The author reports no conflict of interest.

\section{Response}

We very much appreciate the thoughtful comments of Professor Srinivasan. Two questions were raised. The first is whether it would have been more accurate to report rates of GTR and GTR+NTR for all reoperations rather than just those in which GTR was the goal of surgery. The second question is whether the results should have been presented separately for those who received prior radiation versus those who had not received prior radiation therapy.

To address the first question, we wish to highlight that our conclusions only support reoperation over radiation therapy for those craniopharyngiomas for which the surgeon estimates that GTR can be achieved. If GTR cannot be achieved, and there are no symptoms of mass effect, then radiation is often the more reasonable treatment option. However, in the subset of patients in whom GTR can be achieved, our results show that success is as likely as in a first-time operation. For this reason, we separately reported the results of patients in whom GTR was the goal of surgery. To report rates of GTR in patients undergoing palliative debulking does not accurately reflect the success or failure of the intended goals of surgery.
The second question was more of a suggestion to show the results of reoperation in patients who received prior radiation therapy compared with those who did not. We presented our data in just this manner and found that prior radiation reduced the chances of achieving GTR. This result further supports our contention that reoperation should be offered before radiation therapy for recurrent craniopharyngiomas if GTR can be achieved since waiting until after radiation therapy will reduce the chances of success.

We would also like to challenge Prof. Srinivasan's statement that radiation is the "standard option" and the implication that attempts to pursue any other treatment course should not be undertaken. Such assumptions are based on reviews of the existing literature. However, the scientific literature is a dynamic phenomenon, and the precise goal of our article is to challenge the current literature by presenting updated results.

Theodore H. Schwartz, MD

Weill Cornell Medical College, NewYork-Presbyterian Hospital, New York, NY

INCLUDE WHEN CITING

Published online December 23, 2016; DOI: 10.3171/2016.9.JNS162481.

(c)ANS, 2017 